\title{
Perioperative Acute Kidney Injury
}

\section{Risk Factors and Predictive Strategies}

\author{
Charles Hobson, MD, MHA ${ }^{a}$, Rupam Ruchi, $\mathrm{MD}^{\mathrm{b}}$, \\ Azra Bihorac, MD, Ms ${ }^{\mathrm{b}, *}$
}

\section{KEYWORDS}

- Acute kidney injury • AKI • Prediction scores • CEUS • BOLD MRI • DWI MRI

- Biomarkers

\section{KEY POINTS}

- Acute kidney injury is common and is associated with many adverse perioperative outcomes.

- Clinical risk factors for AKI vary in different surgical populations, and preventable risk factors are often underappreciated before surgery.

- Surgical patients should have a systematic preoperative assessment of kidney health, with an emphasis on the patient's renal reserve and susceptibility to new injury.

- The exposure to any intraoperative risk, and the extent of any renal damage, needs to be evaluated using a combination of clinical parameters, biomarkers and imaging techniques.

\section{INTRODUCTION}

Acute kidney injury (AKI) is a common and morbid complication in surgical patients and is associated with significant increases in mortality, an increased risk for chronic kidney disease (CKD) and hemodialysis after discharge, and increased cost and resource utilization. ${ }^{1-11}$ It is characterized by inappropriate oliguria and/or an increase in serum creatinine levels beyond normal. Perioperative AKI complicates the hospital course for up to $50 \%$ of surgical patients. ${ }^{1,2,12-16}$ Despite this impact

Conflicts of Interest and Source of Funding: No authors report conflicts of interest. A. Bihorac is supported by the P50 GM-111152 grant from the National Institute of General Medical Sciences and by the R01 GM-110240 grant from the National Institute of Health and has received research grants from the Society of Critical Care Medicine and Astute Medical, Inc. R. Ruchi and $\mathrm{C}$. Hobson report no grant funding.

a Department of Health Services Research, Management, and Policy, 1225 Center Drive, HPNP 4151 University of Florida Gainesville, FL 32611, USA; ${ }^{b}$ Department of Medicine, University of Florida, PO Box 100254, Gainesville, FL 32610-0254, USA

* Corresponding author.

E-mail address: ABihorac@anest.ufl.edu 
AKI remains among the most underdiagnosed and undertreated postoperative complications. Better understanding of the risk factors that contribute to perioperative $\mathrm{AKI}$ has led to recent advances in AKI prediction and will eventually lead to improved prevention of $\mathrm{AKI}$, mitigation of injury when AKI occurs, and enhanced recovery in patients who sustain AKI. The development of advanced clinical prediction scores for $\mathrm{AKI}$, new imaging techniques that enable more accurate detection of renal injury, and urinary and serum biomarkers of injury for early detection of AKI provides new tools toward these ends. Surgery provides a unique environment for the study of $\mathrm{AKI}$, as the physiologic stress on the kidney at the time of surgery provides a welldefined opportunity for both risk stratification and the initiation of protective and preventive strategies.

\section{DEFINITIONS AND EPIDEMIOLOGY}

Before the development of consensus definitions of AKI, the reported incidence of AKI in the surgical population varied from $1 \%$ to $31 \%$. The tendency was to focus on severe, and relatively rare, $\mathrm{AKI}$ as defined by large increases in serum creatinine and/or the need for dialysis. ${ }^{17,18}$ In 2004 the original Risk, Injury, Failure, Loss, and End-stage Kidney (RIFLE) consensus definition for AKI was released by the Acute Dialysis Quality Initiative. The RIFLE criteria graded less severe AKI stages and provided taxonomies for both severity and recovery. ${ }^{19}$ The current guidelines from Kidney Disease: Improving Global Outcomes (KDIGO) modified the RIFLE criteria to include changes in creatinine as small as $0.3 \mathrm{mg} / \mathrm{dL}^{20}$ (Table 1). The KDIGO guidelines also provide an updated staging system from CKD (Table 2). The epidemiology of perioperative kidney disease has been almost completely redefined since the publication of these consensus definitions.

The consensus definition of AKI has not been uniformly incorporated into the clinical registries and databases used in the surgical community. The American College of Surgeons' (ACS) Committee on Trauma defines AKI as a serum creatinine increase greater or equal to $3.5 \mathrm{mg} / \mathrm{dL}$, and the Society of Thoracic Surgeons Quality Performance Measures defines postoperative renal failure as an increase of serum creatinine to $4.0 \mathrm{mg} /$ $\mathrm{dL}$ or greater or 3 times the most recent preoperative creatinine level. The ACS National Surgical Quality Improvement Project (NSQIP) defines AKI as an increase in serum creatinine greater than $2 \mathrm{mg} / \mathrm{dL}$ from patients' baseline or as the acute need for renal replacement therapy (RRT). ${ }^{21}$ Studies using the ACS NSQIP database typically have high mortality associated with a low incidence of reported $\mathrm{AKI}$, giving the perception that AKI in surgical patients is rare and often fatal. ${ }^{22}$ It has been shown that the ACS NSQIP definition for AKI severely underestimates the incidence of $A K I$, as defined by consensus criteria, in postoperative patients. ${ }^{12}$ The incidence of $\mathrm{AKI}$ in recent studies using current consensus criteria ranges from $25 \%$ in trauma patients ${ }^{2}$ to as high as $75 \%$ for patients undergoing ruptured abdominal aortic aneurysm repair. ${ }^{23}$

\section{OUTCOMES}

Postoperative AKI has been demonstrated to be common and associated with increased incidence of CKD, increased incidence of other postoperative complications, increased risk for short- and long-term mortality, and much higher cost and resource utilization compared with patients with no postoperative AKI. 2,3,5,12,24-32 Two recent studies have demonstrated a continuous risk-adjusted association between postoperative increase in serum creatinine and worse clinical outcomes, and this association persisted at lower cutoffs than in the original RIFLE definition. ${ }^{12,24}$ The adverse effects of AKI persist for years even for those patients who demonstrate partial or even full recovery in renal function by the time of hospital discharge..$^{3,4}$ 


\begin{tabular}{|c|c|c|c|c|c|}
\hline \multicolumn{6}{|c|}{$\begin{array}{l}\text { Table } 1 \\
\text { Consensus definitions for acute kidney injury }\end{array}$} \\
\hline \multicolumn{2}{|c|}{ Stage } & \multicolumn{2}{|c|}{ Serum Creatinine or Glomerular Filtration Rate Criteria } & \multicolumn{2}{|c|}{ Urine Output Criteria } \\
\hline RIFLE & KDIGO & RIFLE & KDIGO & RIFLE & KDIGO \\
\hline Risk & 1 & $\begin{array}{c}\text { Increased } \mathrm{s} C \mathrm{r} \geq 1.5 \text { times } \\
\text { baseline or } \mathrm{GFR} \\
\text { decreased }>25 \%\end{array}$ & $\begin{array}{l}\text { Increased } \mathrm{sCr} 1.5-1.9 \text { times } \\
\text { baseline or } \geq 0.3 \mathrm{mg} / \mathrm{dL} \\
\text { increase }\end{array}$ & $\begin{array}{l}\text { Urine output }<0.5 \mathrm{~mL} / \mathrm{kg} / \mathrm{h} \\
\quad \text { for } \geq 6 \mathrm{~h}\end{array}$ & $\begin{array}{l}\text { Urine output }<0.5 \mathrm{~mL} / \mathrm{kg} / \mathrm{h} \\
\text { for } 6-12 \mathrm{~h}\end{array}$ \\
\hline Injury & 2 & $\begin{array}{l}\text { Increased } \mathrm{sCr} \geq 2 \text { times } \\
\text { baseline or GFR } \\
\text { decreased }>50 \%\end{array}$ & $\begin{array}{l}\text { Increased sCr 2.0-2.9 times } \\
\text { baseline }\end{array}$ & $\begin{array}{l}\text { Urine output }<0.5 \mathrm{~mL} / \mathrm{kg} / \mathrm{h} \\
\text { for } \geq 12 \mathrm{~h}\end{array}$ & $\begin{array}{l}\text { Urine output }<0.5 \mathrm{~mL} / \mathrm{kg} / \mathrm{h} \\
\text { for } \geq 12 \mathrm{~h}\end{array}$ \\
\hline Failure & 3 & $\begin{array}{l}\text { Increased } \mathrm{sCr} \geq 3 \text { times } \\
\text { baseline or } \mathrm{GFR} \\
\text { decreased }>75 \% \text { or } \mathrm{sCr} \\
\geq 4 \mathrm{mg} / \mathrm{dL} \text { (acute increase } \\
\quad \geq 0.5 \mathrm{mg} / \mathrm{dL} \text { ) }\end{array}$ & $\begin{array}{l}\text { Increased sCr } 3.0 \text { times } \\
\text { baseline; or increase in } \\
\mathrm{s} C r \text { to } \geq 4.0 \mathrm{mg} / \mathrm{dL} \text {; or } \\
\text { initiation of RRT; or in } \\
\text { patients }<18 \text { y of age, } \\
\text { decrease in eGFR to } \\
<35 \mathrm{~mL} / \mathrm{min} / 1.73 \mathrm{~m}^{2}\end{array}$ & $\begin{array}{l}\text { Urine output }<0.3 \mathrm{~mL} / \mathrm{kg} / \mathrm{h} \\
\text { for } \geq 24 \mathrm{~h} \text { or anuria for } \\
\geq 12 \mathrm{~h}\end{array}$ & $\begin{array}{l}\text { Urine output }<0.3 \mathrm{~mL} / \mathrm{kg} / \mathrm{h} \\
\text { for } \geq 24 \mathrm{~h} \text { or anuria for } \\
\geq 12 \mathrm{~h}\end{array}$ \\
\hline
\end{tabular}

Abbreviations: eGFR, estimated glomerular filtration rate; GFR, glomerular filtration rate; RRT, renal replacement therapy; sCr, serum creatinine. 


\begin{tabular}{|c|c|c|}
\hline \multicolumn{3}{|c|}{$\begin{array}{l}\text { Table } 2 \\
\text { Chronic kidney disease staging according to National Kidney Foundation kidney disease } \\
\text { outcomes quality initiative guidelines }\end{array}$} \\
\hline Stage & Description & Estimated GFR, ${ }^{a} \mathrm{~mL} / \mathrm{min} / 1.73 \mathrm{~m}^{2}$ \\
\hline & At increased risk & $\geq 90$ (if CKD risk factors present) \\
\hline 1 & Kidney damage with normal or increased GFR & $\geq 90$ \\
\hline 2 & Kidney damage with mildly decreased GFR & $60-89$ \\
\hline$\underline{3}$ & Moderately decreased GFR & $30-59$ \\
\hline 4 & Severely decreased GFR & $15-29$ \\
\hline 5 & Kidney failure & $<15$ (or dialysis) \\
\hline
\end{tabular}

Abbreviation: GFR, glomerular filtration rate.

a Estimated glomerular filtration rate (GFR) is an estimate of kidney function and is calculated using an equation that includes serum creatinine, age, race, and sex. Most of clinical laboratories will report a corresponding estimated GFR when reporting serum creatinine.

Data from Kidney Disease: Improving Global Outcomes (KDIGO) Acute Kidney Injury Work Group. KDIGO clinical practice guideline for acute kidney injury. Kidney Inter Suppl 2012;2:1-138.

Perioperative AKI is independently associated with a high risk for cardiovascularspecific mortality in diverse patient populations, a risk that is comparable with that observed with $\mathrm{CKD} .^{33,34}$ In surgical patients who sustain $\mathrm{AKI}$, the risk-adjusted average cost for an episode of care was $\$ 42,600$ compared with $\$ 26,700$ for patients with no kidney injury. ${ }^{1}$ Recognition of the prevalence and importance of $\mathrm{AKI}$ in surgical patients is the first step in improving perioperative care and in developing quality measures that could translate into improved care for surgical patients.

\section{RISK FACTORS}

Many perioperative factors have been shown to be predictors of AKI after surgery. Scoring systems used to attempt to predict the risk of AKI after cardiac surgery have relied primarily on preoperative clinical and demographic variables. ${ }^{35}$ Systems using genetic polymorphisms for selected inflammatory and vasoconstrictor genes have shown a 2- to 4-fold improvement over clinical factors alone in explaining postcardiac surgery $\mathrm{AKI}^{36}$ Preoperative factors, including total lymphocyte count less than 1500 cells per microliter and elevated C-reactive protein, have been shown to be associated with postcardiac surgery AKI. ${ }^{37,38}$ Preoperative factors related to the procedure itself increase the predictive power for patients undergoing noncardiac surgery. ${ }^{39}$ The Norton scale score of risk for developing a pressure ulcer and preoperative use of diuretics and nonsteroidal antiinflammatory drugs (NSAIDs) have been associated with AKI following total hip arthroplasty. ${ }^{40,41}$ The use of fenestrated grafts and high doses of intravenous contrast are associated with a higher risk for AKI among patients undergoing endovascular abdominal aortic aneurysm repair. ${ }^{42}$ In patients sustaining severe trauma, an increase in serum creatinine, an increase in lactic acid, low body temperature, and any transfusion of blood products in the first day after admission were associated with the development of $\mathrm{AKI}^{2}$ (see Table 1). The Model for End-Stage Liver Disease score, but not pretransplantation creatinine values, was predictive of $\mathrm{AKI}$ among patients undergoing liver transplantation. ${ }^{43}$ Creating a risk score for AKI applicable to all patients has proven to be challenging.

Many important risk factors for AKI are preventable yet often ignored in surgical patients. Preoperative assessment of kidney function, combining estimated glomerular filtration rate (eGFR) using serum creatinine with albuminuria, is one of the most 
valuable yet often underutilized clinical resources for clinicians. It is important both to evaluate for the risk for $\mathrm{AKI}$ and to quantitate the risk for all postoperative morbidity and mortality. CKD, affecting $5 \%$ of the US population, ${ }^{44}$ is an independent predictor of cardiovascular morbidity and mortality. ${ }^{45}$ An association between CKD severity and postoperative death comparable with that seen with diabetes, stroke, and coronary disease was seen in a review of 31 studies of patients undergoing elective surgery. ${ }^{46}$ The adjusted hazard ratio for 30-day mortality in a study using the ACS NSQIP database for patients with CKD ranged from 2.30 (stage $3 \mathrm{CKD}$ ) to 3.05 (stage $5 \mathrm{CKD}$ ) compared with patients with no CKD. ${ }^{47}$ Preoperative proteinuria without CKD was associated with a risk for $\mathrm{AKI}$ and was a powerful independent predictor of all-cause mortality and end-stage renal disease after cardiac surgery. ${ }^{48,49}$ Some perioperative risk indicator scores consider CKD an important prognostic factor in postoperative risk assessment, ${ }^{50-52}$ whereas others do not. ${ }^{53,54}$ One issue is that there is a complicated and poorly understood relationship between serum creatinine and the eGFR, which is calculated in many electronic health records. ${ }^{55}$ Serum creatinine alone often does not give an accurate picture of the presence of CKD, as creatinine values within normal limits may correspond to a low eGFR, particularly in women and the elderly. Use of the eGFR, if available, can help to assure that CKD is evaluated as a risk factor for both $\mathrm{AKI}$ and for overall postoperative mortality.

Many potentially modifiable risk factors for AKI, in both cardiac and noncardiac surgery, include hemodilution, hemoglobin level, intraoperative transfusion, any hypotension, inadequate oxygen delivery, the use of diuretics, the use vasopressors and inotropes, and the use of cardiopulmonary bypass. ${ }^{56-59}$ Interventions to optimize blood flow and pressure during surgery, including the use of invasive hemodynamic monitoring, showed no difference in short-term mortality; but the rates of kidney injury were significantly reduced. ${ }^{60}$ Goal-directed intraoperative management to reduce the risk of postoperative $\mathrm{AKI}$ through optimizing renal perfusion is both feasible and underutilized. Preoperative medications have also been extensively evaluated as both risk and protective factors for a variety of postoperative complications. Several retrospective studies exploring any association between the preoperative use of statins and postoperative AKI have given conflicting results. ${ }^{61-63}$ In a recent retrospective study of 98,939 patients undergoing major surgery, the preoperative use of statins was associated with a $20 \%$ to $26 \%$ reduction in the incidence of $\mathrm{AKI}$ as defined by consensus criteria. ${ }^{64}$ These results, and the wide-ranging pleiotropic actions of statins, have prompted several pending prospective trials evaluating the effect of statins on perioperative complications, including AKI.

\section{PREDICTIVE STRATEGIES}

The risk for postoperative complications, including AKI, arises from the interactions between patients' preoperative health that determines the physiologic capacity to withstand surgery-related stress, modulated by the type and quality of surgery and anesthesia that patients experience. Assessment of surgical risk requires accurate and dynamic synthesis of the large amount of collected clinical information to determine both susceptibility to acute stress and the magnitude of its effect on physiologic homeostasis. During surgery, intraoperative monitors capture complex physiologic time series data reflecting ongoing response to anesthesia and surgery. Given time constraints and the increasing information load on physicians, most of the gathered data can only be screened for overt abnormalities and then discarded. With widespread adoption of electronic health records and advancements in computational power and techniques, use of real-time predictive analytics of clinical data will emerge as 
the most efficient initial approach for identification of patients at high risk for AKI. Once identified, the high-risk patients can be subjected to incrementally more complex and expensive evaluations with emerging biological biomarkers and imaging techniques depending on the response to initial low-cost and low-risk preventive therapies. This section outlines key clinical risk score, imaging, and biological marker techniques that can be applied in current clinical practice. The authors also provide an example of a pragmatic single-institution approach to standardized clinical assessment and management plans for AKI.

\section{CLINICAL RISK SCORES}

The utility of existing AKI scores is limited by several factors, including the use of severe AKI as an end point, restrictions in type of surgery, and lack of dynamic adjustment for preoperative and intraoperative risk factors. Huen and Parikh ${ }^{35}$ performed a systematic review of studies among cardiac surgery patients ${ }^{35}$ and reported 4 clinical risk scores for $\mathrm{AKI}$ requiring dialysis, ${ }^{65-68}$ all of which were limited to preoperative variables, and 3 scores to predict a broader definition of AKI. ${ }^{69-71}$ Two of the smaller studies included intraoperative data to calculate postoperative scores. The receiver operating characteristic-area under the curve (AUC) varied between 0.77 and 0.84 in both internal and validation cohorts, and most of the studies reported an array of common predictors using mainly logistic regression analysis as a computational tool. Two more recent studies in the United Kingdom and Australia used larger data registries for development and validation of predictive scores that included several intraoperative variables, although model performance remained less than $0.82 .{ }^{72,73}$ For patients undergoing noncardiac surgery, few preoperative predictive models were developed, using either only severe AKI as an end point or limiting inclusion to a specific type of surgery. ${ }^{22,32}$ Thottakkara and colleagues ${ }^{74}$ recently reported a machine-learning computational approach for the development of a KDIGO AKI preoperative forecasting model, using the electronic health records of patients undergoing any type of major surgery. They used 59 variables and reported an AUC of 0.86 in the internal validation cohort. ${ }^{74}$ Only a few studies have used intraoperative data in developing a predictive model for noncardiac surgery, and they showed only modest predictive power. ${ }^{75-77}$

Lack of sophistication in data access and analysis in real-time has limited the use of the large volume of complex physiologic time series data generated during surgery for the development of prediction models. To date published postoperative risk scores have used only a snapshot value for hemodynamic monitoring data, such as a mean or lowest value for blood pressure, rather than using time series data applied in their continuity and complexity. An ability to rapidly apply machine learning computational approaches to intraoperative clinical data and physiologic time series data raises the prospect of real-time risk prediction for perioperative $A K I$ as studies using these approaches are emerging. ${ }^{24,78,79}$

\section{IMAGING TECHNIQUES}

Imaging techniques, including standard and Doppler ultrasound, have been used for years to help determine the cause of CKD in patients with a transplanted kidney and in patients at risk for renal artery stenosis. Three techniques have recently been developed to help assess AKI: the renal resistive index (RRI) measured using Doppler ultrasound, contrast-enhanced ultrasound (CEUS), and blood oxygenation leveldependent (BOLD) MRI. 


\section{RENAL RESISTIVE INDEX}

Doppler ultrasound imaging can detect gross vascular abnormalities in the kidney as well as microvascular disorders. RRI, as determined by Doppler ultrasonography, is a measure of pulsatile blood flow that reflects the resistance to flow in the microvasculature. It quantifies changes in both renal vascular resistance and compliance, and an elevated $\mathrm{RRI}$ is associated with an increased risk for AKI. ${ }^{80}$ An increased RRI has been shown to be associated with AKI associated with sepsis. ${ }^{81-84}$ In the immediate postoperative period after cardiac surgery with cardiopulmonary bypass, the RRI predicts both the development of $\mathrm{AKI}$ and its severity. ${ }^{85,86}$ The prediction of AKI by RRI as measured with intraoperative transesophageal echocardiography, for patients undergoing cardiac surgery, is comparable with that obtained by RRI through translumbar ultrasound. ${ }^{87}$ Elevated $\mathrm{RRI}$ is associated with $\mathrm{AKI}$ in orthopedic surgery and in critically ill patients in the medical intensive care unit (ICU). ${ }^{88-90} \mathrm{RRI}$ has also been shown to be useful in predicting the progression of postoperative AKI. ${ }^{91}$ Although RRI depends on renal vascular resistance and compliance, there are other factors that affect RRI, especially in unstable patients; the indications for the test are evolving. ${ }^{92,93}$

\section{CONTRAST-ENHANCED ULTRASOUND}

CEUS has been used for years to help assess solid and cystic lesions in the kidney. ${ }^{94,95}$ It has more recently been used to assess renal perfusion. ${ }^{96}$ In patients undergoing elective cardiac surgery who were considered to be at risk of AKI, renal perfusion as measured using CEUS decreased significantly within 24 hours after surgery. ${ }^{97}$ CEUS shows early promise in assessing both the risk and prognosis of $\mathrm{AKI}$ in surgical patients. ${ }^{98-100}$

\section{MRI}

$\mathrm{MRI}$ is evolving as a technique to aid in diagnosis of AKI. Newer contrast agents, including ultrasmall particles of iron oxide, are less toxic and are being used to study renal blood flow and volume. ${ }^{101}$ BOLD MRI uses deoxyhemoglobin as a nontoxic and endogenous contrast agent for the study of intrarenal oxygenation. ${ }^{102}$ The technique of BOLD MRI has been used to demonstrate changes in renal blood flow related to the use of nephrotoxins, including NSAIDs, intravenous contrast agents, and calcineurin inhibitors. ${ }^{103}$ It has also been used to study changes in renal blood flow associated with CKD and hypertension. ${ }^{104-106}$ Despite the utility of BOLD MRI in studying renal oxygenation and function in animal models of AKI, ${ }^{107,108}$ one recent study evaluating BOLD MRI in the evaluation of $\mathrm{AKI}$ in humans found no correlation between MRI findings and glomerular filtration rate (GFR). ${ }^{109}$ Another recently developed MRI technique known as diffusion-weighted imaging (DWI) detects the motion of water molecules within tissue and has been used to assess renal fibrosis in both $\mathrm{AKI}$ and $\mathrm{CKD} .{ }^{79}$ As with $\mathrm{RRI}$, the indications and utility of BOLD MRI and DWI MRI for predicting AKI in surgical patients are not yet characterized.

\section{USE OF URINE AND PLASMA BIOMARKERS}

A new approach for assessing kidney injury is the analysis of serum and/or urine biomarkers. Early recognition of kidney injury using serum creatinine is problematic as creatinine is a measure of renal function not injury. The ideal biomarker will reveal early evidence of cellular stress before permanent damage even occurs. Serum troponins are useful as biomarkers for cardiac injury because they rapidly reflect myocardial stress and injury. Several urine and serum biomarkers have been studied for their ability to predict kidney stress and injury. ${ }^{110-115}$ Many biomarkers fail because of a lack of 
sensitivity to early cellular stress, a lack of specificity to renal injury, because they cannot differentiate AKI from CKD, and because they are also elevated by the disease process that has caused the AKI. The variety of stressors faced by surgical patients also makes the search for an effective biomarker difficult. The disease process and/ or surgical procedure often results in cellular stress and injuries in several organs, complicated by hemodynamic instability requiring fluid and vasopressor support, blood transfusion, and exposure to nephrotoxic drugs.

Biomarkers to detect kidney injury have been most widely studied in cardiac surgery. Early studies identified plasma and urine neutrophil gelatinase-associated lipocalin (NGAL) as a potential biomarker. ${ }^{116,117}$ Inflammation induces NGAL synthesis and its release from neutrophils throughout the body. A recent summary of NGAL in cardiac surgery patients demonstrated only moderate ability to discriminate AKI from other organ injury. ${ }^{114}$ Studies of critically ill patients in both medical and surgical ICUs showed similar moderate discriminative performance. ${ }^{83,118}$ The inability to discriminate between systemic and kidney-specific effects has limited the clinical use of NGAL.

A more kidney-specific functional biomarker that has undergone extensive evaluation, especially in pediatric patients, is cystatin $\mathrm{C}(\mathrm{CyC}) .{ }^{119,120} \mathrm{CyC}$ is a protease inhibitor produced by all nucleated cells of the body, released at a constant rate, filtered by the glomeruli, and then completely reabsorbed in the renal tubules. CyC is not normally found in urine; thus, the presence of urinary CyC may reflect early kidney injury. Because of the constant rate of its production, plasma CyC concentrations may be a better marker than serum creatinine of GFR; it has recently been proposed as a replacement for serum creatinine in the routine evaluation of GFR rather than as a biomarker of AKI. ${ }^{120,121}$ The role of $\mathrm{CyC}$ in risk stratification for postoperative AKI among surgical patients remains to be defined. ${ }^{112}$

A combination of 2 novel urinary biomarkers has recently been validated as a marker for AKI and has been approved by the US Food and Drug Administration to assess the risk of developing AKI in critically ill patients. Tissue inhibitor of metalloproteinases-2 (TIMP-2) and insulinlike growth factor binding protein 7 (IGFBP7) are cell-cycle arrest proteins, expressed by renal tubular cells and released into the urine during periods of stress due to toxin exposure, hypoxia, and inflammation, among others. Thus, these urinary biomarkers may indicate risk for injury before any actual AKI takes place. ${ }^{122}$

Several multicenter studies have shown that the combination of urinary TIMP-2 and IGFBP7 (TIMP-2•IGFBP7) was predictive of moderate to severe AKI in critically ill patients within 12 hours. ${ }^{123-125}$ The power of the TIMP-2•IGFBP7 test to predict the risk of AKI in these studies was superior to serum creatinine and to other measured biomarkers. $\mathrm{Pa}-$ tients with a TIMP-2•IGFBP7 higher than $0.3(\mathrm{ng} / \mathrm{mL})^{2} / 1000$ had 7 times the risk for AKI (95\% confidence interval 4-22) compared with patients with lower values. A validation study confirmed the high sensitivity and high negative predictive values of $89 \%$ and $97 \%$, respectively, for the cutoff of $0.3 .^{126}$ The development and validation of this biomarker combination is an important advance in early and accurate diagnosis of AKI.

\section{A PRAGMATIC APPROACH}

The use of standardized clinical assessment and management plans that synthesize current medical knowledge with best clinical judgment decreases practice variability and improves patient care better than clinical guidelines. ${ }^{127}$ Considering the high prevalence of AKI, and the adverse outcomes when it occurs, efforts at the authors' institution have focused on prevention of $\mathrm{AKI}$, mitigation of further injury when AKI has already occurred, treatment of negative effects on other organs, and facilitation of renal recovery in patients with established AKI. 
Using KDIGO clinical guidelines as a framework, and using the authors' institutional perioperative registry outcome data, ${ }^{2-4}$ the authors have developed a multistage approach for the determination of kidney health and risk stratification for AKI in the perioperative period and among critically ill surgical patients. This process requires assessment of patients' renal resilience and susceptibility to new injury, the extent of exposure to insult, and the resulting distress or damage sustained by that insult. The determination and management of potential causes of AKI, initiation of interventions, and reassessment of kidney distress in response to that therapy follows promptly afterward. This clinical pathway requires a medical team of experts that not only defines the standardization pathway for the institutions but also provides backup for the bedside care providers.

\section{PREOPERATIVE PATHWAY}

In the preoperative period an accurate assessment of kidney health is important because the extent of previous kidney disease significantly increases susceptibility to the acute stress of surgery. Assessment of renal resilience to acute insult requires a search for any evidence of previous functional or structural kidney damage. Review of the medical history should include diagnosis and staging of known CKD, evidence of previous AKI episodes, and presence of risk factors for CKD. The determination of functional renal reserve with a kidney stress test ${ }^{128}$ may be indicated for more precise risk stratification among patients without apparent CKD who may be considered as high risk because of age or other comorbidities, such as hypertension, chronic obstructive pulmonary disease, vascular disease, diabetes, or liver disease.

\section{POSTOPERATIVE PATHWAY}

For those surgical patients admitted to an ICU, an assessment of kidney health is considered part of a detailed ICU admission assessment. All steps of this process, including the clinical risk stratification, the assessment of tubular distress, and the initiation of treatment, should occur within the first 12 to 24 hours of the ICU admission. Every patient admitted to the authors' ICU undergoes a simple, yet systematic assessment of kidney health. Assessment of renal resilience requires a review of the medical history for diagnosis and staging of known CKD, evidence of previous AKI episodes, and the presence of any risk factors for AKI and CKD. For each patient, the authors perform a calculation of eGFR using reference serum creatinine and, when available, a measurement of albuminuria with urine dipstick or random microalbumin/creatinine ratio tests as an inexpensive snapshot of baseline kidney function. The exposure to insult is quantified by a search of the preceding 24 hours for any evidence of hypotension, use of vasopressors or nephrotoxic medications, sepsis, severe trauma, or any other conditions associated with a high risk for AKI.

Based on this process, the authors have developed an automated algorithm built into the electronic health record note to quantify a clinical risk score for AKI (range 0-16). Patients with a low clinical risk for AKI can undergo usual ICU care. Only patients with a high score $(\geq 3)$ are further tested for kidney stress using the urinary biomarker TIMP-2•IGFBP7. In the authors' experience, approximately $40 \%$ of new admissions to the surgical ICU have a high clinical risk score. Only patients with both a high clinical risk score and a high urinary biomarker test result are considered to be at high risk for AKI and are subjected to the authors' AKI bundle of diagnostic tests and preventive measures during the subsequent 48 hours in an attempt to prevent or ameliorate kidney injury (Fig. 1). 


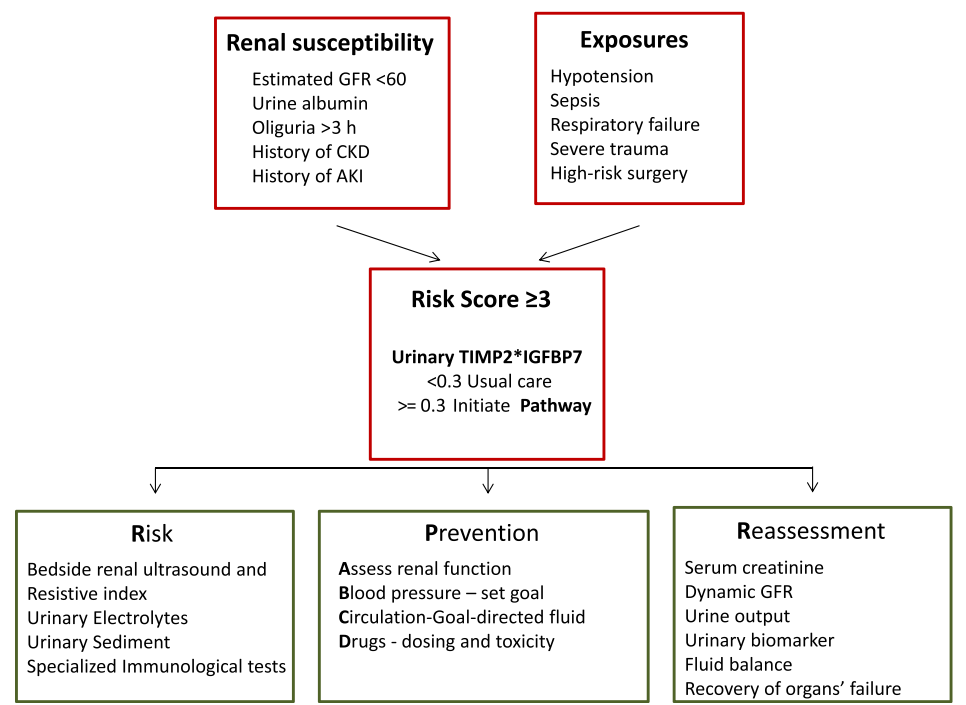

Fig. 1. A clinical pathway for evaluating and managing AKI. (From Bihorac A. Critical controversies: Guiding AKI prevention using biomarkers. Available at: http://www.sccm. org/Communications/Critical-Connections/Archives/Pages/Guiding-AKI-Prevention-UsingBiomarkers.aspx. Accessed August 10, 2016.)

This set of parallel clinical action pathways (risk, prevention, and reassessment) is focused on the identification of the cause of $\mathrm{AKI}$, initiation of preventive therapies, and daily reassessment of the kidney response to initiated therapies. This set is more comprehensive than the KDIGO AKI management options (Fig. 2). This process

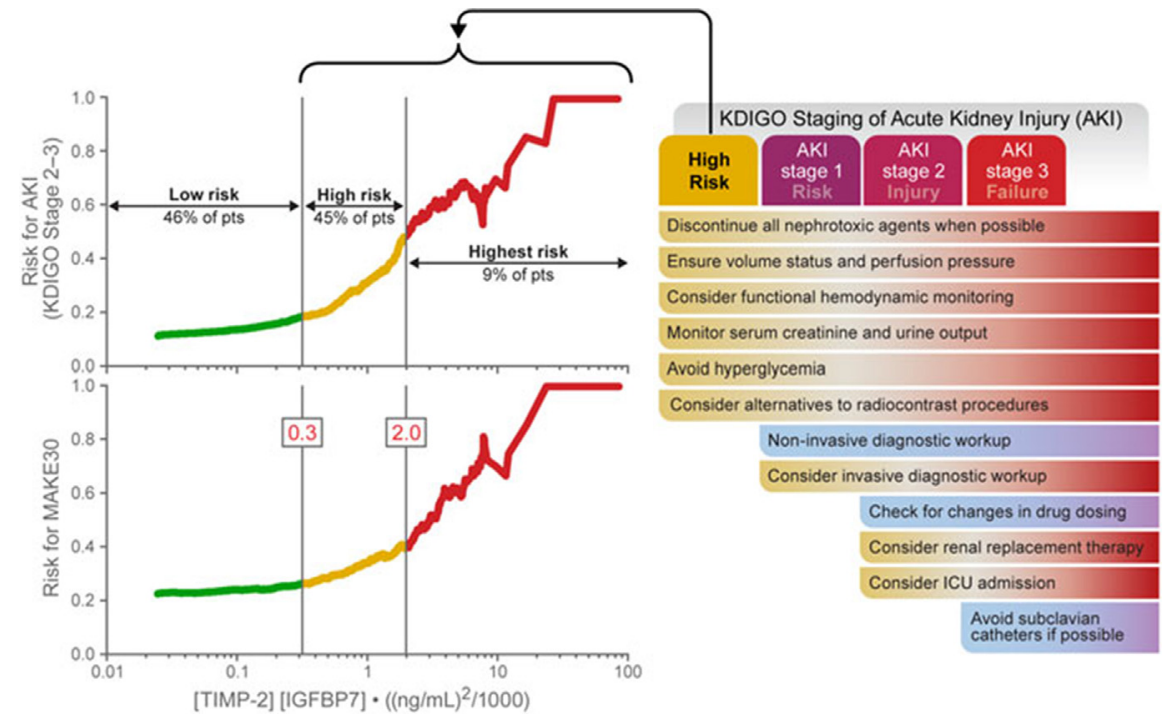

Fig. 2. AKI management options. pts, patients. (Data from Kellum JA. Acute kidney injury and AKI biomarkers in the ICU. Southeaster Critical Care Summit. 2016; Adapted from Kidney Disease: Improving Global Outcomes (KDIGO) Acute Kidney Injury Work Group. KDIGO clinical practice guideline for acute kidney injury. Kidney Inter Suppl 2012;2:1-138.) 
may involve specialized clinical, laboratory, and imaging tools and represents a coordinated effort between the ICU and nephrology teams. Preventive therapies include monitoring and optimizing hemodynamic status by goal-directed fluid management and blood pressure control, strict avoidance of nephrotoxic medications, monitoring of drug levels, and avoiding side effects by adjusting drug dosing in accordance with the GFR. The goal of this phase is to prevent the progression of tubular distress toward functional decline whenever possible and to avoid the negative consequences of fluid overload and drug toxicity in patients with established tubular distress and, thus, it is hoped, to prevent any decline in renal function. The consideration for early RRT may be appropriate for patients with large levels of tubular distress and rapid functional decline, whereby impaired handling of fluids may endanger other organs.

The authors' preliminary experience with protocol implementation and compliance was excellent. One obstacle to implementation was the high cost of the TIMP2.IGFBP7 urinary biomarker test, which the authors overcame by limiting use of the test to those indications standardized within this protocol. Whether this implementation translates into better outcomes will require further evaluation and analysis.

\section{SUMMARY}

$\mathrm{AKI}$ is common and is associated with many adverse perioperative outcomes. Mild to moderate $\mathrm{AKI}$ is much more common than severe $\mathrm{AKI}$ and has become much more appreciated with the introduction of consensus definitions for AKI. All stages of AKI severity are associated with increased morbidity and mortality. Clinical risk factors for AKI vary in different surgical populations, and preventable risk factors are often underappreciated before surgery. Efforts must focus on better identification of risk factors, better risk stratification and, thus, prediction of $\mathrm{AKI}$ in susceptible patients, and ultimately the prevention of $\mathrm{AKI}$ if possible or the facilitation of renal recovery in those patients who sustain AKI. Every surgical patient should have a systematic preoperative assessment of kidney health, with an emphasis on patients' renal reserve and susceptibility to new injury. In the postoperative period the exposure to any intraoperative risk, and the extent of any renal damage, needs to be evaluated using a combination of clinical parameters, novel biomarkers, and evolving imaging techniques. The prompt initiation of treatment and measures to prevent further renal injury, and to promote renal recovery, can then be instituted.

\section{REFERENCES}

1. Hobson C, Ozrazgat-Baslanti T, Kuxhausen A, et al. Cost and mortality associated with postoperative acute kidney injury. Ann Surg 2015;261(6):1207-14.

2. Bihorac A, Delano MJ, Schold JD, et al. Incidence, clinical predictors, genomics, and outcome of acute kidney injury among trauma patients. Ann Surg 2010;252(1):158-65.

3. Hobson CE, Yavas S, Segal MS, et al. Acute kidney injury is associated with increased long-term mortality after cardiothoracic surgery. Circulation 2009; 119(18):2444-53.

4. Bihorac A, Yavas S, Subbiah S, et al. Long-term risk of mortality and acute kidney injury during hospitalization after major surgery. Ann Surg 2009;249(5):851-8.

5. Wald R, Quinn RR, Luo J. Chronic dialysis and death among survivors of acute kidney injury requiring dialysis. JAMA 2009;302(11):1179-85.

6. van Kuijk JP, Flu WJ, Chonchol M, et al. Temporary perioperative decline of renal function is an independent predictor for chronic kidney disease. Clin J Am Soc Nephrol 2010;5(7):1198-204. 
7. Ishani A, Nelson D, Clothier B, et al. The magnitude of acute serum creatinine increase after cardiac surgery and the risk of chronic kidney disease, progression of kidney disease, and death. Arch Intern Med 2011;171(3):226-33.

8. James MT, Ghali WA, Knudtson ML, et al. Associations between acute kidney injury and cardiovascular and renal outcomes after coronary angiography. Circulation 2011;123(4):409-16.

9. Thakar CV, Christianson A, Himmelfarb J, et al. Acute kidney injury episodes and chronic kidney disease risk in diabetes mellitus. Clin J Am Soc Nephrol 2011;6(11):2567-72.

10. Coca SG, Jammalamadaka D, Sint K, et al. Preoperative proteinuria predicts acute kidney injury in patients undergoing cardiac surgery. J Thorac Cardiovasc Surg 2012; 143(2):495-502.

11. Chawla LS, Amdur RL, Shaw AD, et al. Association between AKI and long-term renal and cardiovascular outcomes in United States veterans. Clin J Am Soc Nephrol 2014;9(3):448-56.

12. Bihorac A, Brennan M, Ozrazgat Baslanti $T$, et al. National surgical quality improvement program underestimates the risk associated with mild and moderate postoperative acute kidney injury. Crit Care Med 2013;41(11):2570-83.

13. Borthwick E, Ferguson A. Perioperative acute kidney injury: risk factors, recognition, management, and outcomes. BMJ 2010;341:c3365.

14. Vaught A, Ozrazgat-Baslanti T, Javed A, et al. Acute kidney injury in major gynaecological surgery: an observational study. BJOG 2015;122(10):1340-8.

15. Calvert S, Shaw A. Perioperative acute kidney injury. Perioper Med (Lond) 2012;1:6.

16. Thakar CV. Perioperative acute kidney injury. Adv Chronic Kidney Dis 2013; 20(1):67-75.

17. Hoste EA, Kellum JA. Incidence, classification, and outcomes of acute kidney injury. Contrib Nephrol 2007;156:32-8.

18. Ricci Z, Cruz DN, Ronco C. Classification and staging of acute kidney injury: beyond the RIFLE and AKIN criteria. Nat Rev Nephrol 2011;7(4):201-8.

19. Bellomo R, Ronco C, Kellum JA, et al. Acute renal failure - definition, outcome measures, animal models, fluid therapy and information technology needs: the Second International Consensus Conference of the Acute Dialysis Quality Initiative (ADQI) Group. Crit Care 2004;8(4):R204-12.

20. KDOGI. Clinical practice guideline for acute kidney injury: AKI definition. Kidney Int 2012;2(Suppl 1):19-36.

21. American College of Surgeons National Surgical Quality Improvement Program. User Guide for the 2010 Participant Use Data File. 2010. Available at: http://site. acsnsqip.org/wp-content/uploads/2012/03/2010-User-Guide_FINAL.pdf. Accessed February 25, 2013.

22. Kheterpal S, Tremper KK, Heung M, et al. Development and validation of an acute kidney injury risk index for patients undergoing general surgery: results from a national data set. Anesthesiology 2009;110(3):505-15.

23. van Beek SC, Legemate DA, Vahl A, et al. Acute kidney injury defined according to the 'Risk,' 'Injury,' 'Failure,' 'Loss,' and 'End-stage'(RIFLE) criteria after repair for a ruptured abdominal aortic aneurysm. J Vasc Surg 2014;60(5):1159-67.e1.

24. Ozrazgat Baslanti T, Korenkevych D, Momcilovic P, et al. Mathematical modeling of the association between the pattern of change in postoperative serum creatinine and hospital mortality. Crit Care Med 2012;40(12):U131. 
25. Dimick JB, Pronovost PJ, Cowan JA, et al. Complications and costs after highrisk surgery: where should we focus quality improvement initiatives? J Am Coll Surg 2003;196(5):671-8.

26. Dimick JB, Chen SL, Taheri PA, et al. Hospital costs associated with surgical complications: a report from the private-sector National Surgical Quality Improvement Program. J Am Coll Surgeons 2004;199(4):531-7.

27. Thakar CV, Christianson A, Freyberg R, et al. Incidence and outcomes of acute kidney injury in intensive care units: a Veterans Administration study. Crit Care Med 2009;37(9):2552-8.

28. Duran PA, Concepcion LA. Survival after acute kidney injury requiring dialysis: long-term follow up. Hemodialysis Int 2014;18(S1):S1-6.

29. Coca SG, Yusuf B, Shlipak MG, et al. Long-term risk of mortality and other adverse outcomes after acute kidney injury: a systematic review and meta-analysis. Am J Kidney Dis 2009;53(6):961-73.

30. Lafrance J-P, Miller DR. Acute kidney injury associates with increased long-term mortality. J Am Soc Nephrol 2010;21(2):345-52.

31. Amdur RL, Chawla LS, Amodeo S, et al. Outcomes following diagnosis of acute renal failure in US veterans: focus on acute tubular necrosis. Kidney Int 2009; 76(10):1089-97.

32. Bell S, Dekker FW, Vadiveloo T, et al. Risk of postoperative acute kidney injury in patients undergoing orthopaedic surgery-development and validation of a risk score and effect of acute kidney injury on survival: observational cohort study. BMJ 2015;351:h5639.

33. Ozrazgat-Baslanti T, Thottakkara P, Huber M, et al. Acute and chronic kidney disease and cardiovascular mortality after major surgery. Ann Surg 2016;264(6): 987-96.

34. Huber M, Ozrazgat-Baslanti T, Thottakkara P, et al. Cardiovascular-specific mortality and kidney disease in patients undergoing vascular surgery. JAMA Surg 2016;151(5):441-50.

35. Huen SC, Parikh CR. Predicting acute kidney injury after cardiac surgery: a systematic review. Ann Thorac Surg 2012;93(1):337-47.

36. Stafford-Smith M, Podgoreanu M, Swaminathan M, et al. Association of genetic polymorphisms with risk of renal injury after coronary bypass graft surgery. Am J Kidney Dis 2005;45(3):519-30.

37. Lomivorotov VV, Efremov SM, Boboshko VA, et al. Preoperative total lymphocyte count in peripheral blood as a predictor of poor outcome in adult cardiac surgery. J Cardiothorac Vasc Anesth 2011;25(6):975-80.

38. Kim DH, Shim JK, Hong SW, et al. Predictive value of C-reactive protein for major postoperative complications following off-pump coronary artery bypass surgery: prospective and observational trial. Circ J 2009;73(5):872-7.

39. van Kuijk JP, Flu WJ, Valentijn TM, et al. Preoperative left ventricular dysfunction predisposes to postoperative acute kidney injury and long-term mortality. J Nephrol 2011;24(6):764-70.

40. Asleh K, Sever R, Hilu S, et al. Association between low admission Norton scale scores and postoperative complications after elective THA in elderly patients. Orthopedics 2012;35(9):e1302-6.

41. Aveline C, Leroux A, Vautier $P$, et al. Risk factors for renal dysfunction after total hip arthroplasty. Ann Fr Anesth Reanim 2009;28(9):728-34 [in French].

42. Brooks CE, Middleton A, Dhillon R, et al. Predictors of creatinine rise postendovascular abdominal aortic aneurysm repair. ANZ J Surg 2011;81(11): 827-30. 
43. Romano TG, Schmidtbauer I, Silva FM, et al. Role of MELD score and serum creatinine as prognostic tools for the development of acute kidney injury after liver transplantation. PLoS One 2013;8(5):e64089.

44. Lamb EJ, Levey AS, Stevens PE. The Kidney Disease Improving Global Outcomes (KDIGO) guideline update for chronic kidney disease: evolution not revolution. Clin Chem 2013;59(3):462-5.

45. Matsushita K, van der Velde M, Astor BC, et al. Association of estimated glomerular filtration rate and albuminuria with all-cause and cardiovascular mortality in general population cohorts: a collaborative meta-analysis. Lancet 2010;375(9731): 2073-81.

46. Mathew A, Devereaux PJ, O'Hare A, et al. Chronic kidney disease and postoperative mortality: a systematic review and meta-analysis. Kidney Int 2008;73(9): 1069-81.

47. Gaber AO, Moore LW, Aloia TA, et al. Cross-sectional and case-control analyses of the association of kidney function staging with adverse postoperative outcomes in general and vascular surgery. Ann Surg 2013;258(1):169-77.

48. Wu VC, Huang TM, Wu PC, et al. Preoperative proteinuria is associated with long-term progression to chronic dialysis and mortality after coronary artery bypass grafting surgery. PLoS One 2012;7(1):e27687.

49. Huang TM, Wu VC, Young GH, et al. Preoperative proteinuria predicts adverse renal outcomes after coronary artery bypass grafting. J Am Soc Nephrol 2011; 22(1):156-63.

50. Fleisher LA, Eagle KA. Clinical practice. Lowering cardiac risk in noncardiac surgery. N Engl J Med 2001;345(23):1677-82.

51. Kertai MD, Boersma E, Klein J, et al. Optimizing the prediction of perioperative mortality in vascular surgery by using a customized probability model. Arch Intern Med 2005;165(8):898-904.

52. Lee TH, Marcantonio ER, Mangione CM, et al. Derivation and prospective validation of a simple index for prediction of cardiac risk of major noncardiac surgery. Circulation 1999;100(10):1043-9.

53. Detsky AS, Abrams HB, McLaughlin JR, et al. Predicting cardiac complications in patients undergoing non-cardiac surgery. J Gen Intern Med 1986; 1(4):211-9.

54. Goldman L, Caldera DL, Nussbaum SR, et al. Multifactorial index of cardiac risk in noncardiac surgical procedures. N Engl J Med 1977;297(16):845-50.

55. Levey AS, Stevens LA, Schmid CH, et al. A new equation to estimate glomerular filtration rate. Ann Intern Med 2009;150(9):604-12.

56. Karkouti K, Wijeysundera DN, Yau TM, et al. Acute kidney injury after cardiac surgery: focus on modifiable risk factors. Circulation 2009;119(4): 495-502.

57. Haase M, Bellomo R, Story D, et al. Effect of mean arterial pressure, haemoglobin and blood transfusion during cardiopulmonary bypass on post-operative acute kidney injury. Nephrol Dial Transplant 2012;27(1):153-60.

58. de Somer F, Mulholland JW, Bryan MR, et al. O-2 delivery and CO2 production during cardiopulmonary bypass as determinants of acute kidney injury: time for a goal-directed perfusion management? Crit Care 2011;15(4):R192.

59. Parolari A, Pesce LL, Pacini D, et al. Risk factors for perioperative acute kidney injury after adult cardiac surgery: role of perioperative management. Ann Thorac Surg 2012;93(2):584-91.

60. Grocott Michael PW, Dushianthan A, Hamilton Mark A, et al. Perioperative increase in global blood flow to explicit defined goals and outcomes following 
surgery. Cochrane Database Syst Rev 2012;(11):CD004082. Available at: http:// onlinelibrary.wiley.com/doi/10.1002/14651858.CD004082.pub5/abstract. http:// onlinelibrary.wiley.com/store/10.1002/14651858.CD004082.pub5/asset/CD0040 82. $p d f ? v=1 \& t=h t v v 4 n e t \& s=8117 a 1 c 2 a c 62 c e d f 4 d 7 e 4 f c 5 f 6 d 9 d 0025614 a e 3 d$. http://onlinelibrary.wiley.com/store/10.1002/14651858.CD004082.pub5/asset/CD 004082. $p d f ? v=1 \& t=i 9 c r 70 e s \& s=a 62 c 81 b 3 e 90 d 1 a 75 c 74 a e 3 d 8763 d 6 f d c f 559$ f8ec.

61. Liakopoulos OJ, Kuhn EW, Slottosch I, et al. Preoperative statin therapy for patients undergoing cardiac surgery. Cochrane Database Syst Rev 2012;(4):CD008493.

62. Kor DJ, Brown MJ, Iscimen R, et al. Perioperative statin therapy and renal outcomes after major vascular surgery: a propensity-based analysis. J Cardiothorac Vasc Anesth 2008;22(2):210-6.

63. Molnar AO, Coca SG, Devereaux PJ, et al. Statin use associates with a lower incidence of acute kidney injury after major elective surgery. J Am Soc Nephrol 2011;22(5):939-46.

64. Brunelli SM, Waikar SS, Bateman BT, et al. Preoperative statin use and postoperative acute kidney injury. Am J Med 2012;125(12):1195.

65. Chertow GM, Lazarus JM, Christiansen CL, et al. Preoperative renal risk stratification. Circulation 1997;95(4):878-84.

66. Thakar CV, Arrigain S, Worley S, et al. A clinical score to predict acute renal failure after cardiac surgery. J Am Soc Nephrol 2005;16(1):162-8.

67. Mehta RH, Grab JD, O'Brien SM, et al. Bedside tool for predicting the risk of postoperative dialysis in patients undergoing cardiac surgery. Circulation 2006;114(21):2208-16 [quiz: 2208].

68. Wijeysundera DN, Karkouti K, Dupuis JY, et al. Derivation and validation of a simplified predictive index for renal replacement therapy after cardiac surgery. JAMA 2007;297(16):1801-9.

69. Aronson S, Fontes ML, Miao Y, et al. Risk index for perioperative renal dysfunction/failure: critical dependence on pulse pressure hypertension. Circulation 2007; 115(6):733-42.

70. Palomba H, de Castro I, Neto AL, et al. Acute kidney injury prediction following elective cardiac surgery: AKICS score. Kidney Int 2007;72(5):624-31.

71. Brown JR, Cochran RP, Leavitt BJ, et al. Multivariable prediction of renal insufficiency developing after cardiac surgery. Circulation 2007;116(Suppl 11): |139-43.

72. Birnie K, Verheyden V, Pagano D, et al. Predictive models for Kidney Disease: Improving Global Outcomes (KDIGO) defined acute kidney injury in UK cardiac surgery. Crit Care 2014;18(6):606.

73. Ng SY, Sanagou M, Wolfe R, et al. Prediction of acute kidney injury within 30 days of cardiac surgery. J Thorac Cardiovasc Surg 2014;147(6):1875-83.e1.

74. Thottakkara P, Ozrazgat-Baslanti T, Hupf BB, et al. Application of machine learning techniques to high-dimensional clinical data to forecast postoperative complications. PLoS One 2016;11(5):e0155705.

75. Rueggeberg A, Boehm S, Napieralski F, et al. Development of a risk stratification model for predicting acute renal failure in orthotopic liver transplantation recipients. Anaesthesia 2008;63(11):1174-80.

76. Kheterpal S, Tremper KK, Englesbe MJ, et al. Predictors of postoperative acute renal failure after noncardiac surgery in patients with previously normal renal function. Anesthesiology 2007;107(6):892-902. 
77. Kashani K, Steuernagle JHT, Akhoundi A, et al. Vascular surgery kidney injury predictive score: a historical cohort study. J Cardiothorac Vasc Anesth 2015; 29(6):1588-95.

78. Celi LA, Galvin S, Davidzon G, et al. A database-driven decision support system: customized mortality prediction. J Pers Med 2012;2(4):138-48.

79. Bihorac A. Acute kidney injury in the surgical patient: recognition and attribution. Nephron 2015;131(2):118-22.

80. Ninet S, Schnell D, Dewitte A, et al. Doppler-based renal resistive index for prediction of renal dysfunction reversibility: a systematic review and meta-analysis. J Crit Care 2015;30(3):629-35.

81. Deruddre S, Cheisson G, Mazoit JX, et al. Renal arterial resistance in septic shock: effects of increasing mean arterial pressure with norepinephrine on the renal resistive index assessed with Doppler ultrasonography. Intensive Care Med 2007;33(9):1557-62.

82. Lerolle N, Guerot E, Faisy C, et al. Renal failure in septic shock: predictive value of Doppler-based renal arterial resistive index. Intensive Care Med 2006;32(10): 1553-9.

83. Gornik I, Godan A, Gašparović V. Renal resistive index at ICU admission and its change after 24 hours predict acute kidney injury in sepsis. Crit Care 2014; 18(Suppl 1):P366.

84. Lahmer T, Rasch S, Schnappauf C, et al. Influence of volume administration on Doppler-based renal resistive index, renal hemodynamics and renal function in medical intensive care unit patients with septic-induced acute kidney injury: a pilot study. Int Urol Nephrol 2016;48(8):1327-34.

85. Bossard G, Bourgoin P, Corbeau JJ, et al. Early detection of postoperative acute kidney injury by Doppler renal resistive index in cardiac surgery with cardiopulmonary bypass. Br J Anaesth 2011;107(6):891-8.

86. Regolisti G, Maggiore U, Cademartiri C, et al. Renal resistive index by transesophageal and transparietal echo-Doppler imaging for the prediction of acute kidney injury in patients undergoing major heart surgery. J Nephrol 2016;1-11.

87. Kararmaz A, Kemal Arslantas M, Cinel I. Renal resistive index measurement by transesophageal echocardiography: comparison with translumbar ultrasonography and relation to acute kidney injury. J Cardiothorac Vasc Anesth 2015; 29(4):875-80.

88. Darmon M, Schortgen F, Vargas F, et al. Diagnostic accuracy of Doppler renal resistive index for reversibility of acute kidney injury in critically ill patients. Intensive Care Med 2011;37(1):68-76.

89. Marty P, Szatjnic S, Ferre F, et al. Doppler renal resistive index for early detection of acute kidney injury after major orthopaedic surgery: a prospective observational study. Eur J Anaesthesiol 2015;32(1):37-43.

90. Boddi M, Bonizzoli M, Chiostri M, et al. Renal resistive index and mortality in critical patients with acute kidney injury. Eur J Clin Invest 2016;46(3):242-51.

91. Guinot PG, Bernard E, Abou Arab O, et al. Doppler-based renal resistive index can assess progression of acute kidney injury in patients undergoing cardiac surgery. J Cardiothorac Vasc Anesth 2013;27(5):890-6.

92. Viazzi F, Leoncini G, Derchi LE, et al. Ultrasound Doppler renal resistive index: a useful tool for the management of the hypertensive patient. J Hypertens 2014; 32(1):149-53.

93. Dewitte A, Coquin J, Meyssignac B, et al. Doppler resistive index to reflect regulation of renal vascular tone during sepsis and acute kidney injury. Crit Care 2012;16(5):R165. 
94. Bertolotto M, Cicero C, Perrone R, et al. Renal masses with equivocal enhancement at CT: characterization with contrast-enhanced ultrasound. AJR Am J Roentgenol 2015;204(5):W557-65.

95. Chang EH, Chong WK, Kasoji SK, et al. Management of indeterminate cystic kidney lesions: review of contrast-enhanced ultrasound as a diagnostic tool. Urology 2016;87:1-10.

96. Mahoney M, Sorace A, Warram J, et al. Volumetric contrast-enhanced ultrasound imaging of renal perfusion. J Ultrasound Med 2014;33(8):1427-37.

97. Schneider AG, Goodwin MD, Schelleman A, et al. Contrast-enhanced ultrasound to evaluate changes in renal cortical perfusion around cardiac surgery: a pilot study. Crit Care 2013;17(4):1.

98. Harrois A, Duranteau J. Contrast-enhanced ultrasound: a new vision of microcirculation in the intensive care unit. Crit Care 2013;17(4):449.

99. Legrand MM, Darmon M. Renal imaging in acute kidney injury. Acute nephrology for the critical care physician. Springer; 2015. p. 125-38.

100. Göcze I, Renner P, Graf BM, et al. Simplified approach for the assessment of kidney perfusion and acute kidney injury at the bedside using contrastenhanced ultrasound. Intensive Care Med 2015;41(2):362-3.

101. Choyke P, Kobayashi H. Functional magnetic resonance imaging of the kidney using macromolecular contrast agents. Abdom Imaging 2006;31(2):224-31.

102. Prasad PV, Edelman RR, Epstein FH. Noninvasive evaluation of intrarenal oxygenation with BOLD MRI. Circulation 1996;94(12):3271-5.

103. Hofmann L, Simon-Zoula S, Nowak A, et al. BOLD-MRI for the assessment of renal oxygenation in humans: acute effect of nephrotoxic xenobiotics. Kidney Int 2006;70(1):144-50.

104. Vink E, Boer A, Verloop W, et al. The effect of renal denervation on kidney oxygenation as determined by BOLD MRI in patients with hypertension. Eur Radiol 2015;25(7):1984-92.

105. Vink EE, de Boer A, Hoogduin HJ, et al. Renal BOLD-MRI relates to kidney function and activity of the renin-angiotensin-aldosterone system in hypertensive patients. J Hypertens 2015;33(3):597-603.

106. Pruijm M, Hofmann L, Piskunowicz M, et al. Determinants of renal tissue oxygenation as measured with BOLD-MRI in chronic kidney disease and hypertension in humans. PLoS One 2014;9(4):e95895.

107. Oostendorp M, de Vries EE, Slenter JMGM, et al. MRI of renal oxygenation and function after normothermic ischemia-reperfusion injury. NMR Biomed 2011; 24(2):194-200.

108. Li L-P, Lu J, Zhou Y, et al. Evaluation of intrarenal oxygenation in iodinated contrast-induced acute kidney injury-susceptible rats by blood oxygen leveldependent magnetic resonance imaging. Invest Radiol 2014;49(6):403-10.

109. Inoue $\mathrm{T}$, Kozawa $\mathrm{E}$, Okada $\mathrm{H}$, et al. Noninvasive evaluation of kidney hypoxia and fibrosis using magnetic resonance imaging. J Am Soc Nephrol 2011; 22(8): 1429-34.

110. Vanmassenhove J, Vanholder R, Nagler E, et al. Urinary and serum biomarkers for the diagnosis of acute kidney injury: an in-depth review of the literature. Nephrol Dial Transplant 2013;28(2):254-73.

111. Ostermann M, Philips BJ, Forni LG. Clinical review: biomarkers of acute kidney injury: where are we now? Crit Care 2012;16(5):233.

112. Wasung ME, Chawla LS, Madero M. Biomarkers of renal function, which and when? Clin Chim Acta 2015;438(0):350-7. 
113. Charlton JR, Portilla D, Okusa MD. A basic science view of acute kidney injury biomarkers. Nephrol Dial Transplant 2014;29(7):1301-11.

114. Koyner JL, Parikh CR. Clinical utility of biomarkers of AKI in cardiac surgery and critical illness. Clin J Am Soc Nephrol 2013;8(6):1034-42.

115. Ricci Z, Villa G, Ronco C. Management of AKI: the role of biomarkers. Annual Update in Intensive Care and Emergency Medicine 2015. Springer; 2015. p. 365-77.

116. Martensson J, Bellomo R. The rise and fall of NGAL in acute kidney injury. Blood Purif 2014;37(4):304-10.

117. Hošková L, Franekova J, Málek I, et al. Comparison of cystatin C and NGAL in early diagnosis of acute kidney injury after heart transplantation. Ann Transplant 2015;21. 329-245.

118. Haase M, Bellomo R, Devarajan P, et al. Accuracy of neutrophil gelatinaseassociated lipocalin (NGAL) in diagnosis and prognosis in acute kidney injury: a systematic review and meta-analysis. Am J Kidney Dis 2009; 54(6): 1012-24.

119. Volpon LC, Sugo EK, Carlotti AP. Diagnostic and prognostic value of serum cystatin C in critically ill children with acute kidney injury. Pediatr Crit Care Med 2015;16(5):e125-31.

120. Lagos-Arevalo P, Palijan A, Vertullo L, et al. Cystatin C in acute kidney injury diagnosis: early biomarker or alternative to serum creatinine? Pediatr Nephrol 2015;30(4):665-76.

121. Zappitelli M, Greenberg JH, Coca SG, et al. Association of definition of acute kidney injury by cystatin $\mathrm{C}$ rise with biomarkers and clinical outcomes in children undergoing cardiac surgery. JAMA Pediatr 2015;169(6):583-91.

122. Gocze I, Koch M, Renner P, et al. Urinary biomarkers TIMP-2 and IGFBP7 early predict acute kidney injury after major surgery. PLoS One 2015;10(3):e0120863.

123. Bihorac A, Chawla LS, Shaw AD, et al. Validation of cell-cycle arrest biomarkers for acute kidney injury using clinical adjudication. Am J Respir Crit Care Med 2014;189(8):932-9.

124. Kashani K, Al-Khafaji A, Ardiles T, et al. Discovery and validation of cell cycle arrest biomarkers in human acute kidney injury. Crit Care 2013;17(1):R25.

125. Meersch M, Schmidt C, Van Aken H, et al. Urinary TIMP-2 and IGFBP7 as early biomarkers of acute kidney injury and renal recovery following cardiac surgery. PLoS One 2014;9(3):e93460.

126. Hoste EA, McCullough PA, Kashani K, et al. Derivation and validation of cutoffs for clinical use of cell cycle arrest biomarkers. Nephrol Dial Transplant 2014; 29(11):2054-61.

127. Farias M, Jenkins K, Lock J, et al. Standardized Clinical Assessment and Management Plans (SCAMPs) provide a better alternative to clinical practice guidelines. Health Aff (Millwood) 2013;32(5):911-20.

128. Sharma A, Zaragoza J, Villa G, et al. Optimizing a kidney stress test to evaluate renal functional reserve. Clin Nephrol 2016;86(7):18-26. 